Takefumi Inada MD, Koh Shingu MD, Morio Uchida MD, Shoji Kawachi MD, Kohichi Tsushima MD, Tateki Niitsu MD

\section{Changes in the cerebral arteriovenous oxygen content difference by surgical incision are similar during sevoflu- rane and isoflurane anaesthesia}

sevoflurane group. The $\mathrm{AVDO}_{2}$ was decreased from $6.5 \pm 1.6$ to $5.3 \pm 1.6$ vol\% $(P<0.0005)$ in the sevoflurane group and from $6.7 \pm 1.1$ to $6.0 \pm 1.1$ vol\% $(P<0.01)$ in the isoflurane group. The \% change of $A V D O_{2}$ was larger in the sevoflurane group than in the isoflurane group $(-18.3 \pm 8.4 \%$ us $-9.1 \pm$ $9.0 \% ; P<0.05)$ but no difference remained after the postincisional $\mathrm{AVDO}_{2}$ value of the sevoflurane group was corrected for pre-incisional $\mathrm{PaCO}_{2}$. Carbon dioxide reactivity, calculated as the percent change in $\mathrm{AVDO}_{2}$ per $\mathrm{mmHg}$ change in $\mathrm{PaCO}_{2}$, was $6.1 \pm 3.0 \% \cdot \mathrm{mmHg}^{-1}$ in the sevoflurane group and $5.9 \pm 2.4 \% \cdot \mathrm{mmHg}^{-1}$ in the isoflurane group $(P=N S)$. Conclusions: Sevoflurane and isoflurane are associated with similar impairment of cerebral flow-metabolism coupling at incision, while $\mathrm{CO}_{2}$ reactivity is maintained during both anaesthetics.

Objectif: Étudier les changements de la différence artérioveineuse du contenu en oxygène cérébral $\left(A V D O_{2}\right)$ produits par l'incision et déterminer la réactivité au gaz carbonique $\left(\mathrm{CO}_{2}\right)$ de la circulation cérébrale sous anesthésie au sévoflu. rane et à l'isoflurane.

Méthodes: Vingt et un patients ASA 1 et 2 subissant une chirurgie non urgente pour tumeur supratentorielle ont été aléatoirement assignés à recevoir soit une anesthésie au sévoflurane/ $\mathrm{N}_{2} \mathrm{O}$ 1,3 MAC $(n=10)$ soit une anesthésie à l'isoflurane $\mathrm{N}_{2} \mathrm{O}$ équi-MAC $(n=11)$. Avant et après l'incision, les mesures hémodynamiques ont été effectuées et $\mathrm{AVDO}_{2}$ déterminée. Après l'ouverture de la dure-mère, $\mathrm{AVDO}_{2}$ a été calculée avant et après une augmentation de la fréquence respiratoire de $50 \%$

Résultats: L'incision a provoqué une augmentation de la pression artérielle moyenne respective de $69 \pm 11$ à $97 \pm 22$ mmHg (moyenne $\pm E T)(P<0,0005)$ et $71 \pm 6$ à $89 \pm 12(P<$ $0,0001)$ dans les groupes sévoflurane et isoflurane; la fréquence cardiaque augmentait respectivement de $60 \pm 9$ à 72 $\pm 8 \mathrm{bpm}(P<0,001)$ et de $65 \pm 6$ à $70 \pm 7 \mathrm{bpm}(P<0,001)$. 
Dans le groupe sévoflurane, la $\mathrm{PaCO}_{2}$ augmentait de 33,6 \pm 2,3 à 34,6 $\pm 1,8(P<0,05)$ avec l'incision. Dans le groupe sévoflurane, $A V D O_{2}$ diminuait de $6,5 \pm 1,6$ à $5,3 \pm 1,6$ vol\% $(P$ $<0,0005)$ et dans le groupe isoflurane, de $6,7 \pm 1,1$ à $6,0 \pm 1,1$ vol\% $(P<0,01)$. Le pourcentage de changement de $\mathrm{AVDO}_{2}$ était plus important dans le groupe sévoflurane que dans le groupe isoflurane $(-18,3 \pm 8,4 \%$ vs $-9,1 \pm 9,0 \% ; P<0,05)$; cette différence est disparue une fois la valeur post-incision du groupe sévoflurane corrigée pour la valeur de $\mathrm{PaCO}_{2}$ pré-incision. La réactivité du gaz carbonique, calculée en pourcentage de changement en $\mathrm{AVDO}_{2}$ par $\mathrm{mmHg}$ de changement de $\mathrm{PaCO}_{2}$ était $6,1 \pm 3,0 \% \cdot \mathrm{mmHg}^{-1}$ dans le groupe sévoflurane et $5,9 \pm 2,4 \% \cdot \mathrm{mmHg}^{-1}$ dans le groupe isoflurane $(P=N S)$.

Conclusion: Le sévoflurane et l'isoflurane sont associés à une perturbation identique du couplage débit-métabolisme à l'incision, alors que la réactivité au $\mathrm{CO}_{2}$ est maintenue avec les deux anesthésiques.

Sevoflurane is a new volatile anaesthetic that may be a prefered agent for neurosurgery, because its low blood:gas partition coefficient $(0.60)^{1}$ promotes faster awakening and allows early postoperative neurological examination. Animal studies have shown that sevoflurane does not increase intracranial pressure in hyperventilated $\operatorname{dogs}^{2}$ and that it is indistinguishable from isoflurane with regard to its effects on cerebral haemodynamic variables and metabolism in rabbits. ${ }^{3}$ A clinical study has shown that this agent effectively maintains the cerebral circulation with respect to carbon dioxide $\left(\mathrm{CO}_{2}\right)$ reactivity and autoregulation. ${ }^{4}$

Although sevoflurane and isoflurane appear to have similar effects on cerebral physiology, additional evaluation is required to determine whether sevoflurane is as suitable for neuroanaesthesia as isoflurane, a volatile anaesthetic that has found wide acceptance in neuroanaesthetic practice. Our major concern was to assess whether sevoflurane preserves cerebral flow-metabolism coupling to the same extent as does isoflurane at the time of nociceptive stimulation during surgery. We measured cerebral arteriovenous oxygen content difference $\left(\mathrm{AVDO}_{2}\right)$ to assess cerebral flow-metabolism coupling and used surgical incision as the nociceptive stimulation. Then, we studied the changes of $\mathrm{AVDO}_{2}$ induced by incision during sevoflurane/nitrous oxide $\left(\mathrm{N}_{2} \mathrm{O}\right)$ anaesthesia and isoflurane $/ \mathrm{N}_{2} \mathrm{O}$ anaesthesia in patients with supratentorial tumours. In addition, we determined the $\mathrm{CO}_{2}$ reactivity of the cerebral circulation during both types of anaesthesia.

\section{Methods}

The study was approved by the Hospital Ethics Committee and written informed consent was obtained from each patient. We studied 21 consecutive ASA physical status 1-2 patients who underwent elective surgery for supratentorial tumours. Patients were randomly allocated to receive either sevoflurane $/ \mathrm{N}_{2} \mathrm{O}$ or isoflurane $/ \mathrm{N}_{2} \mathrm{O}$ anaesthesia. Patients with decreased consciousness, a midline shift $>20 \mathrm{~mm}$ on magnetic resonance imaging, cardiopulmonary disease (including hypertension), or a requirement for surgery in the prone position were excluded from the study.

Diazepam $5 \mathrm{mg}$, po and atropine $0.5 \mathrm{mg}, s c$ were given as premedication one hour before induction of anaesthesia. With all routine monitors in place (ECG, arterial catheter, pulse oximetry) and after five minutes stabilization, baseline values of mean arterial pressure (MAP) and heart rate (HR) were recorded. Anaesthesia was induced with thiamylal 3-4 $\mathrm{mg} \cdot \mathrm{kg}^{-1}$, supplemented with fentanyl $2 \mu \mathrm{g} \cdot \mathrm{kg}^{-1}$. One minute before tracheal intubation, $1.5 \mathrm{mg} \cdot \mathrm{kg}^{-1}$ lidocaine $i v$ were given. Tracheal intubation was facilitated with $0.15 \mathrm{mg} \cdot \mathrm{kg}^{-1}$ vecuronium and the lungs were mechanically ventilated to maintain the $\mathrm{PETCO}_{2}$ concentration between 30 and $35 \mathrm{mmHg}$ (Anesthetic Gas Monitor, Type 1304, Brüel \& Kjaer, Denmark). The rectal temperature (RT) was also monitored. Anaesthesia was maintained with $0.8-1.0 \mu \mathrm{g} \cdot \mathrm{kg}^{-1} \cdot \mathrm{hr}^{-1}$ fentanyl and $\mathrm{N}_{2} \mathrm{O}$ at an end-tidal concentration of $65 \%$ ( 0.6 minimum alveolar concentration (MAC)) in oxygen. In addition, either sevoflurane or isoflurane was given at an end-tidal concentration of 0.7 MAC (Bruel \& Kjaer) until the incision was completed. After incision, the concentration of the respective volatile anaesthetic was maintained between 0.5 and 1.5 MAC as necessary until the dura was opened. The MAC of sevoflurane was taken as $1.71 \% ;^{5}$ of isoflurane as $1.15 \% ;^{6}$ and of $\mathrm{N}_{2} \mathrm{O}$ as $104 \%{ }^{7}$ Intermittent doses of vecuronium iv were administered to maintain muscle paralysis. After induction of anaesthesia, a subclavian central venous pressure (CVP) catheter was inserted. The internal jugular bulb on the side contralateral to the major pathology was also cannulated (if the lesion was in the midline, the right side was cannulated) and the catheter tip was confirmed radiographically to be at the level of and just medial to the mastoid process. Normovolaemia was maintained throughout anaesthesia by observing the responses of MAP, HR, and CVP to fluid administration, and colloids and blood products were given as required to maintain a normal CVP.

After at least 20 -min stabilization with the respective agent ( $1.2 \%$ sevoflurane or $0.8 \%$ isoflurane), surgical incision was performed. Just before and after incision, MAP, HR, and RT were recorded, and blood samples were obtained simultaneously from the jugular and arterial lines for the measurement of $\mathrm{AVDO}_{2}(\mathrm{ABL} 505$ and OSM 3, Radiometer, Copenhagen, Denmark). Incision 
was defined as dissection of the skin, connective tissue, and epicranial aponeurosis or temporal fascia, but not the periosteum of the skull. The $\mathrm{AVDO}_{2}$ was calculated as the difference in oxygen content between the arterial and jugular venous blood according to the following formula:

$\mathrm{AVDO}_{2}(\mathrm{vol} \%)=1.39 \times$ haemoglobin $\left(\mathrm{g} \cdot \mathrm{dl}^{-1}\right) \times\left(\mathrm{SaO}_{2}\right.$ $\left.-\mathrm{SjvO}_{2}\right)(\%) / 100+0.003 \times\left(\mathrm{PaO}_{2}-\mathrm{PjvO}_{2}\right)(\mathrm{mmHg})$,

where $\mathrm{SaO}_{2}$ is the arterial oxygen saturation, $\mathrm{SjvO}_{2}$ is the jugular venous oxygen saturation, $\mathrm{PaO}_{2}$ is the arterial oxygen tension, and $\mathrm{PjvO}_{2}$ is the jugular venous oxygen tension.

Carbon dioxide and oxygen tension data were corrected for the body temperature. The haemoglobin concentration was measured separately (Symex E-4000, Towa, Kobe, Japan).

After the dura was opened and $20 \mathrm{~min}$ after 0.7 end-tidal MAC of the test anaesthetic agent with $65 \%$ $\mathrm{N}_{2} \mathrm{O}$ in oxygen was achieved, the respiratory rate was increased by $50 \%$ and the tidal volume was kept constant. Just before and five minutes after the change in ventilation, MAP, $\mathrm{HR}$, and RT were recorded, and blood samples were obtained simultaneously from the jugular and arterial lines for $\mathrm{AVDO}_{2}$ measurement. The relative $\mathrm{CO}_{2}$ reactivity ${ }^{8}$ was determined as \% $\triangle \mathrm{AVDO}_{2} / \triangle \mathrm{PaCO}_{2}$, where the $\% \Delta \mathrm{AVDO}_{2}$ is the percent change in $\mathrm{AVDO}_{2}$ and the $\triangle \mathrm{PaCO}_{2}$ is the difference of arterial $\mathrm{CO}_{2}$ tension in $\mathrm{mmHg}$.

Data are expressed as the mean \pm SD. The patient characteristics, baseline MAP and $\mathrm{HR}$, the induction dose of thiamylal, the time from induction of anaesthesia to incision, the \% change in $\mathrm{AVDO}_{2}$ upon incision, and $\mathrm{CO}_{2}$ reactivity were compared by unpaired Student's $t$ test. Other data were analyzed by two-way repeated measures of analysis of variance (ANOVA). $P<0.05$ was taken to indicate statistical significance.

\section{Results}

The age, height, weight, sex, midline shift of the tumour, and maximum tumour area were similar in both groups (Table I). All patients were fully conscious before surgery, with four patients in the sevoflurane group and five in the isoflurane group receiving glucocorticoid therapy.

Baseline MAP and HR were $87 \pm 10 \mathrm{mmHg}$ and $71 \pm$ $17 \mathrm{bpm}$ in the sevoflurane group and $95 \pm 10 \mathrm{mmHg}$ and $74 \pm 15 \mathrm{bpm}$ in the isoflurane group $(P=\mathrm{NS})$. The induction dose of thiamylal was $3.5 \pm 0.3 \mathrm{mg} \cdot \mathrm{kg}^{-1}$ in the sevoflurane group and $3.7 \pm 0.4 \mathrm{mg} \cdot \mathrm{kg}^{-1}$ in the isoflurane group ( $P=\mathrm{NS}$ ). The time from induction of anaesthesia to incision was $76 \pm 17 \mathrm{~min}$ in the sevoflurane group and $78 \pm 11 \mathrm{~min}$ in the isoflurane group $(P=$
TABLE I Patient characteristics (mean \pm SD). The age, sex, height, weight, midline shift of the tumour, and maximum tumour area were similar in both groups

\begin{tabular}{lcl}
\hline & $\begin{array}{l}\text { Sevoflurane group } \\
(n=10)\end{array}$ & $\begin{array}{l}\text { Isoflurane group } \\
(n=11)\end{array}$ \\
\hline Age (yr) (mean (range)) & $46(27-58)$ & $47(31-64)$ \\
Sex (M/F) & $6 / 4$ & $7 / 4$ \\
Height $(\mathrm{cm})$ & $160 \pm 9$ & $164 \pm 9$ \\
Weight $(\mathrm{kg})$ & $59 \pm 13$ & $60 \pm 15$ \\
Midline shift (mm) & $3 \pm 4$ & $2 \pm 6$ \\
Maximum tumour area $\left(\mathrm{cm}^{2}\right)$ & $8 \pm 5$ & $9 \pm 3$ \\
\hline
\end{tabular}

NS). The MAP, HR, $\mathrm{PaCO}_{2}$, and RT before and after incision also showed no differences between the groups (Table II). Incision increased MAP $(P<0.0005$ and $P<$ 0.0001 in the sevoflurane and isoflurane groups, respectively) and $\mathrm{HR}(P<0.001)$ in both groups, and also increased $\mathrm{PaCO}_{2}(P<0.05)$ in the sevoflurane group. The $\mathrm{AVDO}_{2}$ was decreased by incision in both groups $(P<0.0005$ and $P<0.01$ in the sevoflurane and isoflurane groups, respectively), although the \% change in $\mathrm{AVDO}_{2}$ upon incision was larger in the sevoflurane group $(-18.3 \pm 8.4 \%)$ than in the isoflurane group $(-9.1$ $\pm 9.0 \%)(P<0.05)$.

The MAP, HR, $\mathrm{PaCO}_{2}, \mathrm{RT}$, and $\mathrm{AVDO}_{2}$ prior to hyperventilation showed no differences between the groups (Table III). After five minutes of hyperventilation, MAP, HR, and RT did not change. Hyperventilation decreased $\mathrm{PaCO}_{2}(P<0.0001)$ and increased $\mathrm{AVDO}_{2}(P<0.0001)$ in both groups, but the \% $\triangle \mathrm{AVDO}_{2} / \triangle \mathrm{PaCO}_{2}$ was not different.

\section{Discussion}

In the present study, we determined the changes in $\mathrm{AVDO}_{2}$ caused by surgical incision. The aim was to assess the anaesthetic stability of cerebral flow-metabolism coupling in the presence of nociceptive stimulation, with the assumption that $\mathrm{AVDO}_{2}$ reflects the ratio of cerebral metabolic rate for oxygen $\left(\mathrm{CMRO}_{2}\right)$ to $\mathrm{CBF}$ $\left(\mathrm{AVDO}_{2}=\mathrm{CMRO}_{2} / \mathrm{CBF}\right)$ and that surgical incision is a representative nociceptive stimulus. We considered that such a study design was clinically relevant for the following reasons. Most previous studies concerning the cerebrovascular and metabolic effects of anaesthesia have been performed under steady state conditions without stimulation, although surgical patients are frequently subjected to various noxious stimuli. Therefore, we felt that it was important to assess not only the effects of anaesthesia on the balance between $\mathrm{CMRO}_{2}$ and $\mathrm{CBF}$, but also the effects of surgical stimulation on this balance during anaesthesia. Surgical incision may increase the MAP by sympathetic stimulation and an abrupt 
TABLE II Physiological variables before and after incision

\begin{tabular}{|c|c|c|c|c|c|c|}
\hline & $\begin{array}{l}M A P \\
(m m H g)\end{array}$ & $\begin{array}{l}H R \\
(b p m)\end{array}$ & $\begin{array}{l}\mathrm{PaCO}_{2} \\
(\mathrm{mmHg})\end{array}$ & $R T\left({ }^{\circ} \mathrm{C}\right)$ & $\begin{array}{l}A V D O_{2} \\
(\text { vol \%) }\end{array}$ & $\begin{array}{l}\text { Percent } \\
\text { change in } \\
\mathrm{AVDO}_{2}(\%)\end{array}$ \\
\hline \multicolumn{7}{|c|}{ Sevoflurane group } \\
\hline Before incision & $69 \pm 11$ & $60 \pm 9$ & $33.6 \pm 2.3$ & $36.4 \pm 0.5$ & $6.5 \pm 1.6$ & \multirow{2}{*}{$-18.3 \pm 8.4$} \\
\hline After incision & $97 \pm 22 \S$ & $72 \pm 8 \ddagger$ & $34.6 \pm 1.8^{*}$ & $36.3 \pm 0.5$ & $5.3 \pm 1.6 \S$ & \\
\hline \multicolumn{7}{|l|}{ Isoflurane group } \\
\hline Before incision & $71 \pm 6$ & $65 \pm 6$ & $33.6 \pm 2.2$ & $36.4 \pm 0.6$ & $6.7 \pm 1.1$ & \multirow{2}{*}{$-9.1 \pm 9.0$} \\
\hline After incision & $89 \pm 12 \mathbb{I}$ & $70 \pm 7 \ddagger$ & $33.7 \pm 1.9$ & $36.4 \pm 0.6$ & $6.0 \pm 1.1 \dagger$ & \\
\hline
\end{tabular}

$* P<0.05, \dagger P<0.01, \ddagger P<0.001, \S P<0.0005, q P<0.0001$ vs before incision. $\| P<0.05$ between the groups. Values are mean \pm SD. MAP: mean arterial pressure; $\mathrm{HR}$ : heart rate; $\mathrm{PaCO}_{2}$ : arterial carbon dioxide tension; $\mathrm{RT}$ : rectal temperature; $\mathrm{AVDO}_{2}$ : cerebral arteriovenous oxygen content difference.

TABLE III Physiological variables before and after hyperventilation

\begin{tabular}{lllllll}
\hline & $\begin{array}{l}\mathrm{MAP} \\
(\mathrm{mmHg})\end{array}$ & $\begin{array}{l}\mathrm{HR} \\
(\mathrm{bpm})\end{array}$ & $\begin{array}{l}\mathrm{PaCO}_{2} \\
(\mathrm{mmHg})\end{array}$ & $R T\left({ }^{\circ} \mathrm{C}\right)$ & $\begin{array}{l}A V D O_{2} \\
(\mathrm{vol} \%)\end{array}$ & $\begin{array}{l}\mathrm{CO}_{2} R \\
\left(\% \cdot m m \mathrm{Hg}^{-1}\right)\end{array}$ \\
\hline $\begin{array}{l}\text { Sevoflurane group } \\
\text { Before hyperventilation }\end{array}$ & $85 \pm 13$ & $70 \pm 12$ & $33.2 \pm 2.1$ & $36.1 \pm 0.6$ & $6.0 \pm 2.0$ & $6.1 \pm 3.0$ \\
After hyperventilation & $85 \pm 13$ & $71 \pm 13$ & $27.6 \pm 2.6^{*}$ & $36.1 \pm 0.6$ & $7.7 \pm 2.4^{*}$ & \\
& & & & & & \\
Isoflurane group & & & & & & \\
Before hyperventilation & $76 \pm 10$ & $70 \pm 10$ & $33.0 \pm 2.4$ & $36.2 \pm 0.5$ & $6.2 \pm 1.1$ & $5.9 \pm 2.4$ \\
After hyperventilation & $76 \pm 10$ & $70 \pm 10$ & $27.7 \pm 2.3^{*}$ & $36.2 \pm 0.5$ & $8.0 \pm 1.2^{*}$ & \\
\hline
\end{tabular}

" $P<0.0001$ vs before hyperventilation. Values are mean $\pm \mathrm{SD}$. $\mathrm{PaCO}_{2}$ : arterial carbon dioxide tension; RT: rectal temperature; $\mathrm{AVDO}_{2}: \mathrm{cerebral}$ arteriovenous oxygen content difference; $\mathrm{CO}_{2} \mathrm{R}$ : relative carbon dioxide reactivity. The $\mathrm{CO}_{2} \mathrm{R}$ was determined as $\% \triangle A V D \mathrm{~A}_{2} / \triangle \mathrm{PaCO}$, where the $\% \triangle \mathrm{AVDO}_{2}$ is the percent change in $\mathrm{AVDO}_{2}$ and the $\triangle \mathrm{PaCO}_{2}$ is the difference of $\mathrm{PaCO}_{2}$ in mmHg. There were no differences between the groups.

increase in MAP may be followed by an increase in $\mathrm{CBF}^{9,10}$ because cerebral autoregulatory mechanisms are not instantaneously initiated. ${ }^{11-13}$ However, an increase in MAP is not the only phenomenon caused by incision, since it may variably increase $\mathrm{CMRO}_{2}$ and $\mathrm{CBF}$ without affecting MAP, depending on the anaesthetic circumstances. ${ }^{14}$ In the present study, incision provoked a decrease of $\mathrm{AVDO}_{2}$ in both groups, indicating that stimulation disturbed the coupling of $\mathrm{CMRO}_{2}$ with $\mathrm{CBF}$ and altered the flow-metabolism balance to a state of relative hyperaemia. Although the $\%$ change in $\mathrm{AVDO}_{2}$ was larger in the sevoflurane group, this was not due to a poor protective effect of sevoflurane anaesthesia against nociceptive stimulation, but rather to the chemically induced increase of $\mathrm{CBF}$ (due to increased $\mathrm{PaCO}_{2}$ ) upon incision. When the post-incisional $\mathrm{AVDO}_{2}$ of the sevoflurane group was corrected for the pre-incisional $\mathrm{PaCO}_{2}$ using the $\mathrm{CO}_{2}$ reactivity $\left(6.1 \pm 3.0 \% \cdot \mathrm{mmHg}^{-1}\right)$, the difference no longer existed. Therefore, sevoflurane anaesthesia appears to be similar to isoflurane anaesthesia with regard to the preservation of coupling during surgical incision.

We calculated $\mathrm{CBF}$ reactivity to $\mathrm{CO}_{2}$ as the $\%$ $\triangle \mathrm{AVDO}_{2} / \triangle \mathrm{PaCO}_{2}{ }^{8}$ The validity of the data is dependent on the assumption that if $\mathrm{CMRO}_{2}$ is constant during hyperventilation, $\mathrm{CBF}$ is inversely proportional to AVDO ${ }_{2}{ }^{15}$ To meet the prerequisite, we obtained data after the dura was opened, because it is a stage when nociceptive stimulation induced by the surgery may be of minor importance and this was supported by the insignificant changes in MAP and HR that ocurrred during hyperventilation. In addition, hyperventilation per se has been reported to have no effect on $\mathrm{CMRO}_{2}{ }^{16} \mathrm{We}$ limited hyperventilation to five minutes, assuming that $\mathrm{CMRO}_{2}$ would be unchanged within this period. Madsen et al. measured $\mathrm{AVDO}_{2}$ changes during hyperventilation, and reported that the relative $\mathrm{CO}_{2}$ reactivity during $0.75 \%$ isoflurane and $67 \% \mathrm{~N}_{2} \mathrm{O}$ /fentanyl anaesthesia was $4.4 \pm 2.6 \% \cdot \mathrm{mm} \mathrm{hg}^{-1}$ during craniotomy in brain tumour patients. ${ }^{17}$ Our patients and mode of anaesthesia were similar to theirs and our isoflurane data (5.9 $\pm 2.4 \% \cdot \mathrm{mmHg}^{-1}$ ) were also similar. The slightly higher value obtained in the present study may be ascribed to a slightly different $\mathrm{PaCO}_{2}$ before hyperventilation (29.7 \pm $3.1 \mathrm{mmHg}$ for Madsen et al. vs $33.0 \pm 2.4 \mathrm{mmHg}$ in our study). A previous study showed that $\mathrm{CO}_{2}$ reactivity 
is well maintained during $0.88 \mathrm{MAC}$ sevoflurane in $33 \% \mathrm{~N}_{2} \mathrm{O}$ in patients with ischaemic cerebrovascular disease. ${ }^{4}$ When the relative $\mathrm{CO}_{2}$ reactivity was calculated from the normocapnic to hypocapnic range from their study, the value obtained $\left(6.9 \pm 4.8 \% \cdot \mathrm{mmHg}^{-1}\right)$ is compatible with ours $\left(6.1 \pm 3.0 \% \cdot \mathrm{mmHg}^{-1}\right)$. Therefore, our results confirmed that $\mathrm{CO}_{2}$ reactivity was maintained during sevoflurane anaesthesia as well as during isoflurane anaesthesia, and revealed comparable values for the two agents.

Our anaesthetic regimen included fentanyl, $\mathrm{N}_{2} \mathrm{O}$, and an induction dose of thiamylal. We assumed that the effects of thiamylal on cerebral flow-metabolism coupling were minimal, because barbiturates were reported to cause a parallel reduction in $\mathrm{CBF}$ and $\mathrm{CMRO}_{2}{ }^{18}$ In addition, the plasma concentration of the drug at the time of incision should have been very low, because the concentration of thiopentone (a barbiturate very similar to thiamylal) is $10 \%$ of its peak value $20-30 \mathrm{~min}^{19}$ after a single intravenous dose. Nitrous oxide may increase both $\mathrm{CBF}^{20-25}$ and $\mathrm{CMRO}^{21,22,24,25}$ and the degree of increases depends on the anaesthetic regimen. ${ }^{22-25}$ Algotsson et al. ${ }^{25}$ compared the $\mathrm{AVDO}_{2}$ during anaesthesia with and without $\mathrm{N}_{2} \mathrm{O}$. Changing from $1.7 \%$ isoflurane in air/oxygen plus fentanyl anaesthesia to $0.85 \%$ isoflurane in $65 \% \mathrm{~N}_{2} \mathrm{O}$ plus fentanyl anaesthesia (equi-MAC) resulted in an increase of $\mathrm{CBF}$ and no change of $\mathrm{CMRO}_{2}$ when $\mathrm{PaCO}_{2}$ was $4.6 \mathrm{kPa}$ (35 $\mathrm{mmHg}$. ${ }^{25}$ Therefore, the $\mathrm{AVDO}_{2}$ values obtained before incision and hyperventilation in our study may be smaller than those during equi-MAC isoflurane/fentanyl anaesthesia without $\mathrm{N}_{2} \mathrm{O}$. Increase in $\mathrm{CBF}$ by $\mathrm{N}_{2} \mathrm{O}$ is reversed or attenuated by hyperventilation. ${ }^{22,23,25}$ Thus, CBF reactivity to $\mathrm{CO}_{2}$ is maintained and has been demonstrated in pigs anaesthetized with fentanyl, $\mathrm{N}_{2} \mathrm{O}$, and pancuronium..$^{16}$ Cerebral blood flow reactivity is greater during isoflurane anaesthesia than during a MAC-equivalent isoflurane $/ \mathrm{N}_{2} \mathrm{O}$ anaesthesia. ${ }^{26}$ Thus, the addition of $\mathrm{N}_{2} \mathrm{O}$ during isoflurane/fentanyl anaesthesia might reduce the $\mathrm{CO}_{2}$ reactivity of the cerebral circulation. However, the applicability of this assumption to sevoflurane/fentanyl anaesthesia could not be determined.

The MAP and HR before and after surgical incision, as well as during hyperventilation, were similar in both groups, findings comparable to results of other studies. ${ }^{27,28}$ There was a small increase of $\mathrm{PaCO}_{2}$ upon incision in the sevoflurane group. Patients in both groups appeared to be equally anaesthetized at the time of incision, since the thiamylal dose for induction and the induction-incision time were not different between the groups and since both volatile agents were equilibrated at an equi-MAC concentration for $20 \mathrm{~min}$. Thus, either increased systemic metabolism or increased wasted ventilation upon incision may be responsible for the increase of $\mathrm{PaCO}_{2}$ in the sevoflurane group. The MAC is determined by motor responses, so equi-MAC conditions do not necessarily indicate that the metabolic response to incision will also be identical.

In summary, surgical incision provoked a similar disturbance of cerebral flow-metabolism coupling to relative hyperaemia during sevoflurane $/ \mathrm{N}_{2} \mathrm{O}$ and isoflurane $/ \mathrm{N}_{2} \mathrm{O}$ anaesthesia. We also confirmed that the $\mathrm{CO}_{2}$ reactivity of the cerebral circulation was well maintained during both types of anaesthesia.

\section{References}

1 Wallin RF, Regan BM, Napoli MD, Stern IJ. Sevoflurane: a new inhalational anesthetic agent. Anesth Analg 1975; 54: 758-65.

2 Takahashi $H$, Murata K, lkeda K. Sevoflurane does not increase intracranial pressure in hyperventilated dogs. Br J Anaesth 1993; 71: 551-5.

3 Scheller MS, Tateishi A, Drummond JC, Zornow MH. The effects of sevoflurane on cerebral blood flow, cerebral metabolic rate for oxygen, intracranial pressure, and the electroencephalogram are similar to those of isoflurane in the rabbit. Anesthesiology 1988; 68: 548-51.

4 Kitaguchi K, Ohsumi H, Kuro M, Nakajima T, Hayashi $Y$. Effects of sevoflurane on cerebral circulation and metabolism in patients with ischemic cerebrovascular disease. Anesthesiology 1993; 79: 704-9.

5 Katoh $T$, Ikeda $K$. The minimum alveolar concentration (MAC) of sevoflurane in humans. Anesthesiology 1987; 66: 301-3.

6 Stevens WC, Dolan WM, Gibbons RT, et al. Minimum alveolar concentrations (MAC) of isoflurane with and without nitrous oxide in patients of various ages. Anesthesiology 1975; 42: 197-200.

7 Hornbein TF, Eger EI II, Winter PM, Smith G, Wetstone $D$, Smith $K H$. The minimum alveolar concentration of nitrous oxide in man. Anesth Analg 1982; 61: 553-6.

8 Obrist WD, Langfitt TW, Jaggi JL, Cruz J, Gennarelli TA. Cerebral blood flow and metabolism in comatose patients with acute head injury. J Neurosurg 1984: 61: 241-53.

9 Moorthy SS, Greenspan CD, Dierdorf SF, Hillier SC. Increased cerebral and decreased femoral artery blood flow velocities during direct laryngoscopy and tracheal intubation. Anesth Analg 1994: 78: 1144-8.

10 Kofke WA, Dong M-L, Bloom M, Policare R, Janosky J, Sekhar $L$. Transcranial Doppler ultrasonography with induction of anesthesia for neurosurgery. J Neurosurg Anesthesiol 1994: 6: 89-97.

11 Greenfield JC Jr, Rembert JC, Tindall GT. Transient changes in cerebral vascular resistance during the Valsalva maneuver in man. Stroke 1984: 15: 76-9. 
12 Aaslid R, Lindegaard K-F, Sorteberg W, Nornes $H$. Cerebral autoregulation dynamics in humans. Stroke 1989: 20: 45-52.

13 Strebel S, Lam AM, Matta B, Mayberg TS, Aaslid R, Newell $D W$. Dynamic and static cerebral autoregulation during isoflurane, desflurane, and propofol anesthesia. Anesthesiology 1995: 83: 66-76.

14 Kuramoto T, Oshita S, Takeshita H, Ishikawa T. Modification of the relationship between cerebral metabolism, blood flow, and electroencephalogram by stimulation during anesthesia in the dog. Anesthesiology 1979: 51: 211-7.

15 Michenfelder JD, Theye RA. The effects of profound hypocapnia and dilutional anemia on canine cerebral metabolism and blood flow. Anesthesiology 1969: 31: 449-57.

16 Åkeson J, Messeter K, Rosén I, Björkman S. Cerebral haemodynamic and electrocortical $\mathrm{CO} 2$ reactivity in pigs anaesthetized with fentanyl, nitrous oxide and pancuronium. Acta Anaesthesiol Scand 1993: 37: 85-91.

17 Madsen JB, Cold GE, Hansen ES, Bardrum B. The effect of isoflurane on cerebral blood flow and metabolism in humans during craniotomy for small supratentorial cerebral tumors. Anesthesiology 1987: 66: 332-6.

18 Boarini DJ, Kassell NF, Coester HC. Comparison of sodium thiopental and methohexital for high-dose barbiturate anesthesia. J Neurosurg 1984: 60: 602-8.

19 Marshall BE, Longnecker DE. General anesthetics. In: Hardman JG, Limbird LE, Molinoff PB, Ruddon RW, Gilman AG (Eds.). The Pharmacological Basis of Therapeutics, 9th ed. New York: McGraw-Hill, 1996: 307-30.

20 Strebel S, Kaufmann $M$, Anselmi L, Schaefer $H G$. Nitrous oxide is a potent cerebrovasodilator in humans when added to isoflurane. A transcranial Doppler study. Acta Anaesthesiol Scand 1995: 39: 653-8.

21 Matta BF, Lam AM. Nitrous oxide increases cerebral blood flow velocity during pharmacologically induced EEG silence in humans. J Neurosurg Anesthesiol 1995: 7 : 89-93.

22 Hoffman WE, Charbel FT, Edelman $G$, Albrecht RF, Ausman JI. Nitrous oxide added to isoflurane increases brain artery blood flow and low frequency brain electrical activity. J Neurosurg Anesthesiol 1995: 7: 82-8.

23 Hörmann Ch, Schmidauer Ch, Haring HP, Schalow S, Seiwald $M$, Benzer A. Hyperventilation reverses the nitrous oxide-induced increase in cerebral flow velocity in human volunteers. Br J Anaesth 1995: 74: 616-8.

24 Lam AM, Mayberg TS, Eng CC, Cooper JO, Bachenberg $K L$, Mathisen $T L$. Nitrous oxide-isoflurane anesthesia causes more cerebral vasodilation than an equipotent dose of isoflurane in humans. Anesth Analg 1994: 78: 462-8.

25 Algotsson L, Messeter K, Rosén I, Holmin T. Effects of nitrous oxide on cerebral haemodynamics and metabolism during isoflurane anaesthesia in man. Acta Anaesthesiol Scand 1992: 36: 46-52.

26 Strebel S, Kaufmann M, Baggi M, Zenklusen U. Cerebrovascular carbon dioxide reactivity during exposure to equipotent isoflurane and isoflurane in nitrous oxide anaesthesia. Br J Anaesth 1993: 71: 272-6.

27 Smith I, Ding $Y$, White PF. Comparison of induction, maintenance, and recovery characteristics of sevoflurane- $\mathrm{N} 2 \mathrm{O}$ and propofol-sevoflurane- $\mathrm{N} 2 \mathrm{O}$ with propofol-isoflurane-N2O anesthesia. Anesth Analg 1992: 74: 253-9.

28 Malan TP Jr, DiNardo JA, Isner RJ, et al. Cardiovascular effects of sevoflurane compared with those of isoflurane in volunteers. Anesthesiology 1995: 83: 918-28. 